\title{
VAGINAL MYOMECTOMY OF A CERVICAL FIBROID IN TERM PREGNANCY.
}

Urmila Tripathi' ${ }^{1}$, Veena Agrawal2 ${ }^{2}$ Sandhya Pradhan ${ }^{3}$.
1. Assistant Professor. Department of Obstetrics and Gynaecology, G.R. Medical College, Gwalior.
2. Professor \& Head of the Department, Department of Obstetrics and Gynaecology, G.R. Medical College, Gwalior.
3. Senior Resident, Department of Obstetrics \& Gynaecology, G.R. Medical College, Gwalior.

\section{CORRESPONDING AUTHOR:}

Dr Urmila Tripathi

C-98, Govind Puri,

Opp. Vice Chancellor's Residence,

Hurawali Road, GWALIOR, M.P.

Pin Code No 474011.

Email-urmilatripathi@gmail.com

INTRODUCTION: The reported prevalence of fibroid in pregnancy is $10.7 \%$ (1). Fibroids necessitating surgery in pregnancy is rare and myomectomy in pregnancy has been reported to be successful in a few series $(2,3)$. Myomectomy may be warranted when there is associated pain not relieved with conservative measures, haemorrhage necessitating transfusion or when degeneration of the fibroid leads to infection. There are only a few reports in the literature outlining vaginal myomectomy of a cervical or prolapsed submucous fibroid $(4,5)$.

CASE REPORT: A thirty eight year old G8P7L6 with 7 prior term vaginal deliveries was referred to our institution on 25/3/13 from a district hospital as a case of 33weeks of pregnancy with pain and a large tumor on posterior wall of cervix. Her EDD was 10/5/13. She was a case of LTT failure which was done 3 year back at district hospital. As per the patient, at third month of gestation she felt dragging sensation in lower abdomen during work. When she went to the hospital she was told about the presence of cervical fibroid, but no treatment was advised.

On Examination Patient was conscious, well oriented to time place and person. Mild pallor was present; pulse rate was 88 beats per minute and blood pressure 120/80 mm Hg. On per abdominal examination fundal height 32 week size, cephalic presentation, FHR regular 132beats/min. P/S examination showed a mass of size of $7 \times 8 \mathrm{~cm}$ was present on the right side of cervix with broad base of $2 \mathrm{~cm}$ diameter arising from 2'O clock to 5'O clock position. P/V examination - cervical os un-effaced, admitted tip of finger, membranes present, no show. Patient was given steroids and tocolytics. Her USG report showed single live intrauterine fetus of 34week with well defined hyperechoic lesion of $7.5 \times 5 \mathrm{~cm}$ seen in posterior wall of cervix suggestive of fibroid. Her blood investigations were within normal limit. Patient was kept on conservative treatment till 37 completed weeks and decision of vaginal myomectomy was taken. We discussed the risks/benefits/alternatives of a vaginal myomectomy and the patient strongly desired surgical management of the tumor. Myomectomy was done under GA documenting the fetal heart rate pre and post surgery. Postoperative period was uneventful. Patient was given injectable hemostatics and tocolytics for first 24hours. After 10 days, i.e. at 38 weeks, patient developed leaking per vaginum, induction done with 25 microgram misoprostol and patient delivered a male baby of 2.2 
kg. Postpartum period was uneventful. Her pathology report showed $6.3 \times 5 \mathrm{~cm}$ leiomyoma containing plasma cells and lymphocytes.

DISCUSSION: The location of the fibroid arising from the cervix allowed us to remove it with little effect on pregnancy. Leiomyomas are most common uterine tumor with an overall incidence of 40$60 \%$ by age 35 and $70-80 \%$ by age $50(6)$. Pregnancy complications that do arise seem to be more common with large leiomyomas, submucosal and those located below the placental attachment. Complications include spontaneous miscarriage, preterm labor, placental abruption, malpresentation, labor dystocia, caesarean delivery and postpartum haemorrhage $(7,8)$. The size of uterine fibroid throughout pregnancy has shown that the majority of fibroids (60-78\%) do not demonstrate any significant change in volume during pregnancy. Of the $22 \%$ to $32 \%$ of fibroid that did increase in volume, the growth was limited almost exclusively to the first trimester especially the first 10weeks of gestation with very little effect, if any, growth in the second and third trimesters (9).

CONCLUSION: The patient under discussion would almost certainly have needed a caesarean section to affect delivery if the tumor had not been excised. A routine gynaecological examination before pregnancy or during the first antenatal visit is very important and should be encouraged not only to diagnose but also to manage such rare problems as well as to diagnose many other diseases during pregnancy.

\section{REFERENCES:}

1. Laughlin SK, Baird DD, Savitz DA, et al. Prevalence of uterine leiomyomas in the first trimester of pregnancy: an ultrasound-screening study. Obstet Gynecol 2009; 113:630-635.

2. De Carolis S, Fatigante G, Ferrazzani S, et al. Uterine myomectomy in pregnant women. Fetal Diagn Ther2001; 16:116-119.

3. Mollica G, Pittini L, Minganti E, et al. Elective uterine myomectomy in pregnant women. Clin Exp Obstet Gynecol1996; 23:168-172.

4. Oruç S, Karaer 0, Kurtul O. Coexistence of a prolapsed, pedunculated cervical myoma and pregnancy complications: a case report. J Reprod Med 2004; 49:575-577.

5. Demirci F, Somunkiran A, Safak AA, et al. Vaginal removal of prolapsed pedunculated submucosal myoma during pregnancy. Adv Ther 2007; 24:903-906.

6. Day Baird D, Dunson DB, Hill MC, Cousins D, Schectman JM. High cumulative incidence of uterine leiomyoma in black and white women: ultrasound evidence. Am J Obstet Gynecol 2003; 188:100-7.

7. Muram D, Gillieson M, Walters JH. Myomas of the uterus in pregnancy: ultrasonographic followup. Am J Obstet Gynecol 1980; 138:16-9.

8. Katz VL, Dotters DJ, Droegemeuller W. Complications of uterine leiomyomas in pregnancy. Obstet Gynecol 1989; 73:593-6.

9. Lee HJ, Norwitz ER, Shaw J. Contemporary management of fibroids in pregnancy. Rev Obstet Gynecol 2010; 3:20-7. 


\section{CASE REPORT}

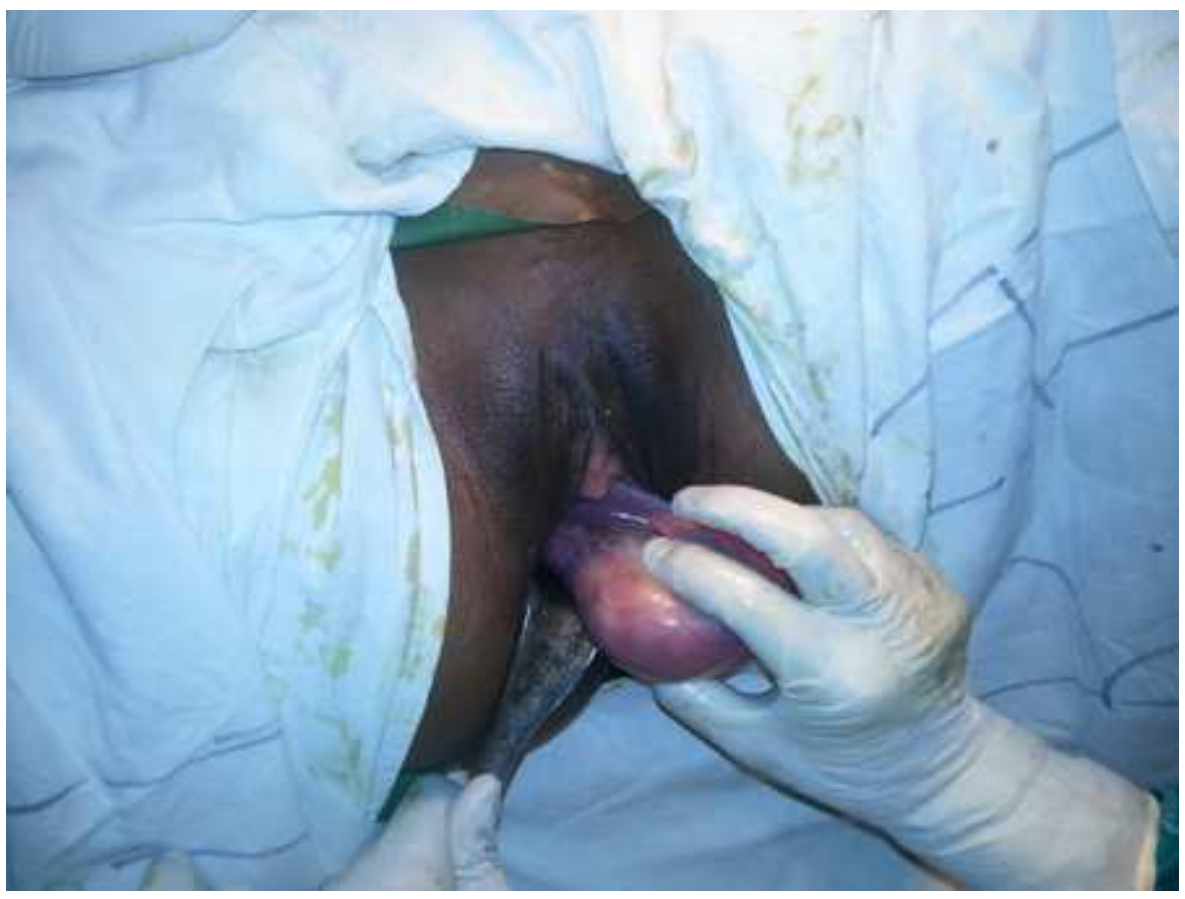

An orange size cervical fibroid prolapsing through interoitus, in a patient with term pregnancy .

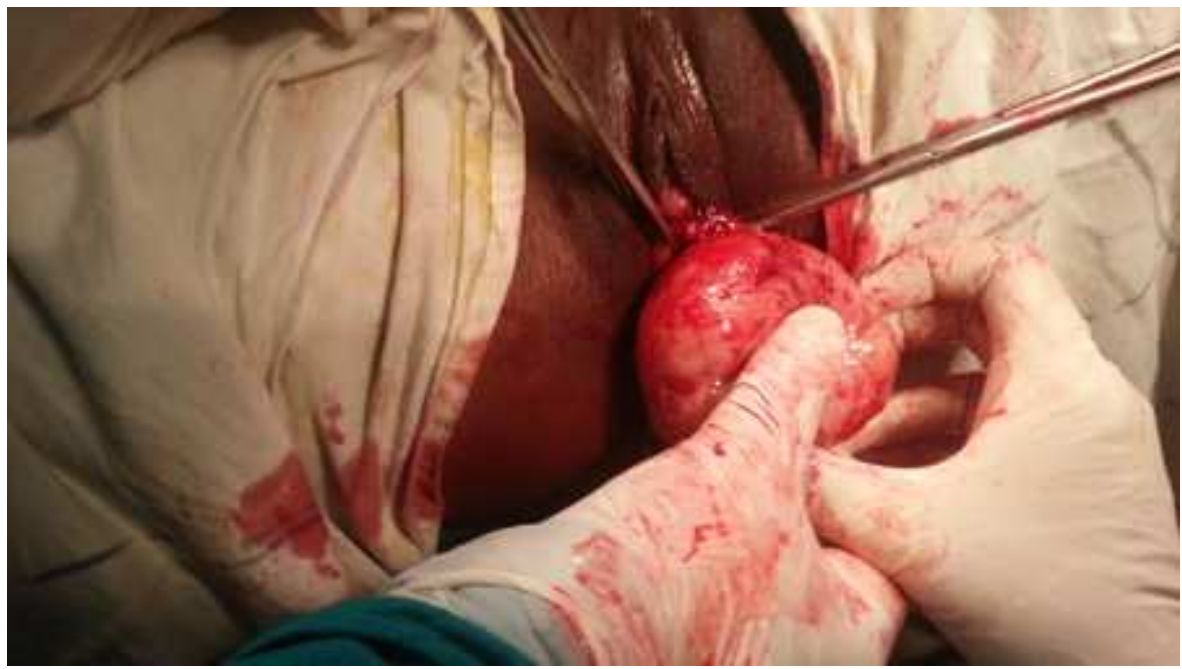

The fibroid capsule has been incised and the base grasped with long curved clamps before myomectomy. 


\section{CASE REPORT}

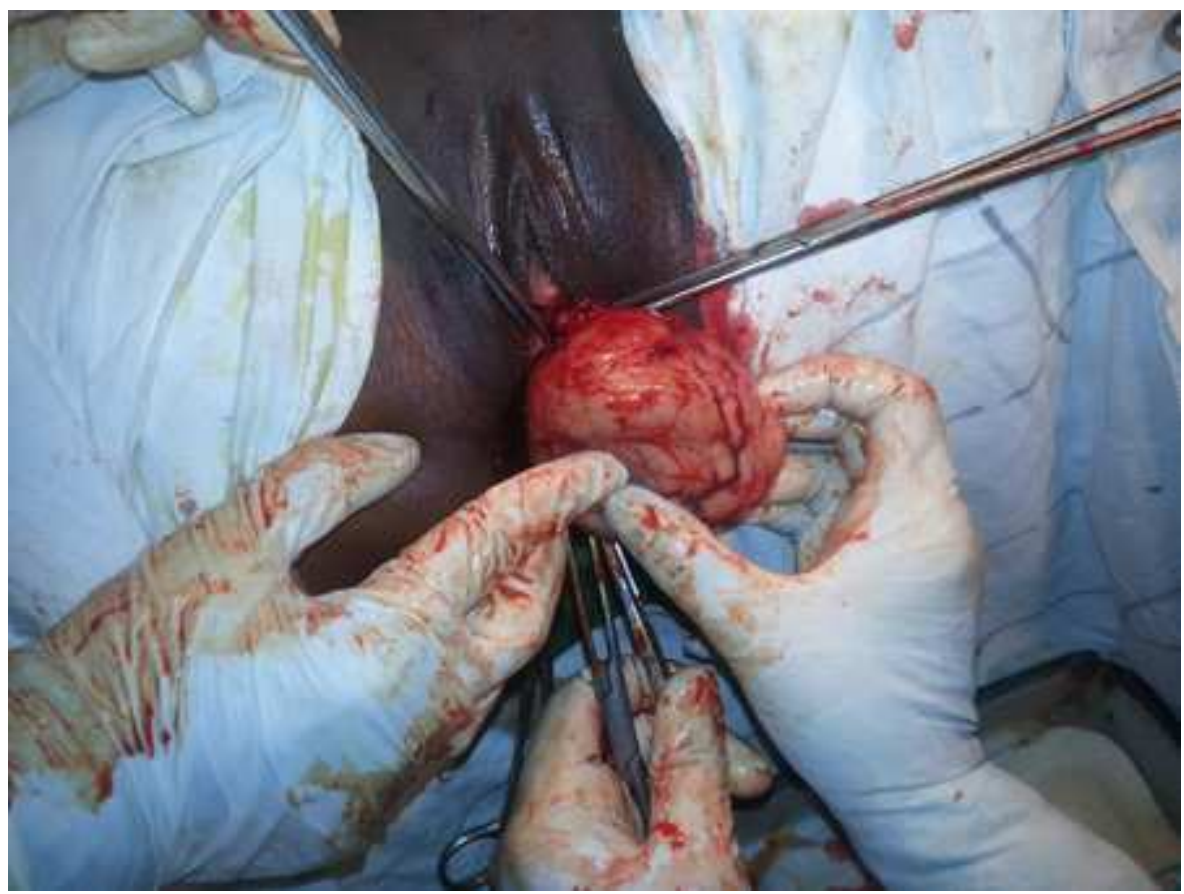

The fibroid capsule has been incised and the base grasped with long curved clamps before myomectomy. (cont.)

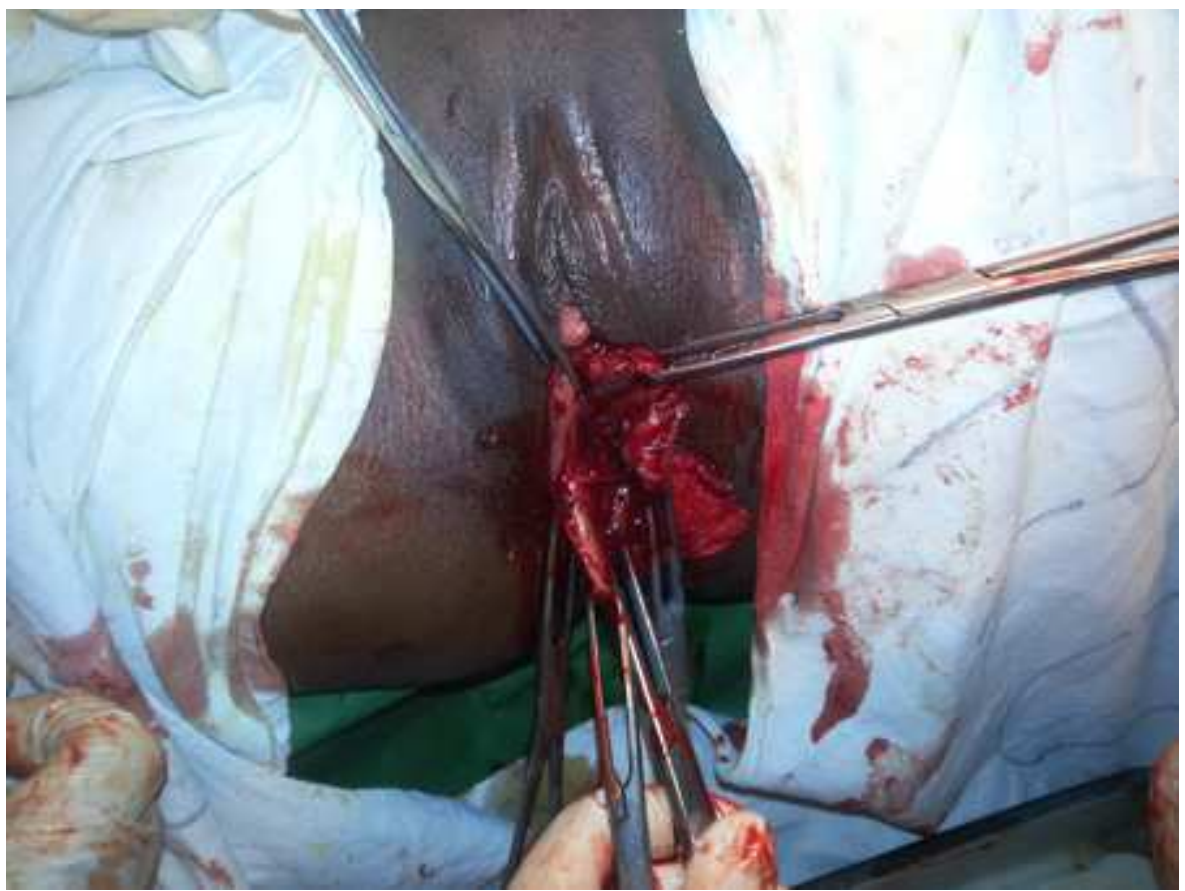

The fibroid capsule held with Allis Forceps' after myomectomy, before placing sutures. 